\title{
Overcoming Mental Health Challenges during Pandemic: Arguing in favour of Incorporation of Community Mental Health in Undergraduate Medical Curriculum
}

\author{
Baijayanti Baur \\ Former-Professor and HOD Department of Community Medicine, Midnapore Medical College, Immediate Past President, \\ Indian Association of Preventive and Social Medicine, WB Chapter
}

The rapid and progressing Covid-19 pandemic is building an upsurge of fear, anxiety and stress globally. Repeated episodes of lock down, physical distancing norms, work from home culture in the new normal scenario, travel restrictions, school shutdown, home isolation and quarantine, bed and oxygen crisis, prolonged hospitalization, post Covid morbidities and deaths, Covid orphans, loss of job, lack of recreation, loneliness and the others cumulatively are contributing to tremendous stress on individual mental health. Though by definition 'Health' includes "mental wellbeing" apart from physical and social wellbeing but the mental health issues have largely been pushed into backstage in this current pandemic conundrum.

Moreover, in this Covid situation, pregnant women are also facing higher stress which may have a negative impact on their mental health and pregnancy outcome. Many independent prospective studies have revealed that when pregnant mother is stressed, anxious or depressed there is increased risk of having a range of problems in her child including emotional problems, Attention Deficit Hyperactive Disorder, conduct disorder and impaired cognitive development. ${ }^{[1]}$ At present, doctor patient relationship is also in question as increasing number of violence are reported in different media platforms. Incidence of suicide, depression, anxiety are also increasing among medical students and doctors due to academic pressure, staying away from home, substance use, lack of healthy relationship with friends or partners. Often young doctors face difficulties in communicating the death news to the bereaved family members, specially to the orphaned children, which adds up to their increasing work stress. Covid-19 pandemic related grief and stress management is thus the need of the hour.

Mental health problems are fairly common all over the world. WHO multi-centric cross cultural study has revealed that about 25 percent of the out- patient department attendees at primary level health care facilities suffer from one or more diagnosable psychiatric disorders. ${ }^{[2]}$ Only 30 to $50 \%$ of psychiatric disorders are diagnosed correctly by primary care physicians due to inadequate exposure to psychiatric problems during undergraduate medical training. ${ }^{[3]}$ Adequate psychiatric training during undergraduate medical training not only increases the clinical competency to diagnose and manage patients with psychiatric illnesses but it also helps in the development of core clinical skills such as listening skills, empathizing ability, effective communication and humanitarian values. ${ }^{[4]}$ The recent study of the four lower and middle income countries of SouthEast Asia (Bangladesh , India, Nepal, and Sri Lanka) revealed wide variations in allocation of time and place in psychiatry at the undergraduate level among the four countries. ${ }^{[5]}$ India has started competency based curriculum from August 2019. ${ }^{[6]}$ But, Psychiatry is still not

CORRESPONDING AUTHOR:Dr Baijayanti Baur, Former-Professor and HOD Department of Community Medicine, Midnapore Medical College, Immediate Past President, Indian Association of Preventive and Social Medicine, WB Chapter E Mail ID: baijayanti baur@yahoo.com

ARTICLE CYCLE: Received: 12/06/2021; Revised: 16/06/2021; Accepted: 23/06/2021; Published:30/06/2021

CITATION: Baur B. Overcoming Mental Health Challenges during Pandemic: Arguing in favour of Incorporation of Community Mental Health in Undergraduate Medical Curriculum.J Comp Health. 2021;9(1):03-04. 
included as a subject in comprehensive list of certifiable procedural skills recommended as desirable for MBBS. At present India is not generating enough psychiatrists as required to tackle the Pandemic related mental health crisis. Moreover the in-service short term training of Medical Officers may not be adequate for their competency development in this regard.

To tackle the mental health problems we have to think judiciously to bring forth feasible alterations within our present infrastructure for betterment of our mental health comprehensively. Some suggestions are put forward for further considerations:

1. The present day undergraduate course curriculum needs inclusion of Community Mental Health/ Community Psychiatry as a separate domain under the Department of Psychiatry to acquire knowledge and skills in mental health and the curriculum to be framed accordingly. One must learn how to diagnose and manage the common mental health problems through history taking and mental status examination. The communication and counselling skills by hands-on-training should be imparted to each MBBS student with help of faculties of Community Medicine, Psychiatry and of course by the Counsellors in an integrated manner. Emphasis should be given to include in the curriculum preconception counselling, maternal stress management, coping with day-to-day stress, communicating death news, first hand management of mental health/ psychiatric emergencies e.g. suicidal tendencies, severe anxiety/panic attacks, substance withdrawal, drug intoxication etc. and referral needs. Pandemic related stress management must be accorded utmost priority. The clinical posting of the students for one month during $6^{\text {th }}$ semester may be very effective at this juncture. During the Third Professional MBBS Part1 Examination, adequate weightage in marks should be given to assess their competency development in this domain. The internship training in Psychiatry for mandatory four weeks may also be suggested for skill development.
2. The Family care booklet of Community Medicine Department ofthe medical colleges may include the proforma of Mental Health Examination for individuals.

Our aim is to provide trained Primary care physicians competent enough to tackle the mental health problems of the community and majority of their mental health issues can be managed efficiently by them.

Professional associations like Indian Association of Preventive and Social Medicine should discuss and deliver on these issues and appropriateadvocacy measures should be initiated at the earliest.

\section{REFERENCES}

1. Glover V. Stress and Pregnancy (Prenatal and Perinatal). Encyclopedia on Early Childhood Development. $\quad$ https://www.childencyclopedia.com/stress-and-pregnancy-prenataland-perinatal/according-experts/effects-prenatalstress-

child\#: : :text=Many\%20independent\%20prospective\% 20studies\%20have,disorder\%20and\%20impaired\%20 cognitive\%20developmentam handle $=123456789 / 13$ 62. Last accessed on 08.06.2021

2. Common mental disorders and disability across cultures: results from the who collaborative study on psychological problems in general health care https://www.researchgate.net/publication/235932252 common mental disorders and disability across $\mathrm{cu}$ ltures results from the who collaborative study on psychological problems in general health care last accessed on 08.06.2021

3. Guidelines for the Management of Common Mental Disorders. Ministry of Health and Family Welfare. Accessed from http://clinicalestablishments.gov.in/WriteReadData/60 6.pdf.Last accessed on 8.06.2021.

4. Kallivayalli RA. The Importance of Psychiatry in Undergraduate Medical Education in India. Indian Journal of Psychiatry.2012.Vol-54. 208-16 . Available from:

https://www.indianjpsychiatry.org/text.asp?2012/54/3/ 208/102336 .Last accessed on 8.06.2021.

5. Arafat SM, Kar SK, Sharma P, Marahatta K Baminiwatta AK. A comparative analysis of psychiatry curriculum at undergraduate level of Bangladesh, India, Nepal, and Sri Lanka. Indian J Psychiatry [serial online] 2021 [cited 2021 Jun 17];63:184-8. Available from:

https://www.indianjpsychiatry.org/text.asp?2021/63/2/ 184/313720.Last accessed on 8.06.2021.

6. UG Curriculum/NMC https://www.nmc.org.in/information-desk/forcolleges/ug-curriculumLast accessed on 18.06.2021 